\title{
REFLEXÕES ENTRE A REGULAÇÃO E A SUPRESSÃO DE DIREITOS A PARTIR DA PESSOALIDADE E SUBORDINAÇÃO NO DIREITO CAPITALISTA DO TRABALHO
}

\author{
REFLECTIONS BETWEEN REGULATION AND SUPPRESSION OF RIGHTS \\ THROUGH PERSONNEL AND SUBORDINATION NON CAPITALIST LABOR \\ RIGHT
}

\section{REFLEXIONES ENTRE LA REGULACIÓN Y LA SUPRESIÓN DE DERECHOS A PARTIR DE LA PERSONALIDAD Y SUBORDINACIÓN EN EL DERECHO CAPITALISTA DEL TRABAJO}

\begin{abstract}
ERICK ALAN DE LIMA
Graduado em Direito pela Pontifícia Universidade Católica do Paraná (UFPR). Especialista em Direito do Trabalho, Processo e Mercado pela Faculdade OPET. Curitiba, Paraná, Brasil. http://lattes.cnpq.br/6564441799115530 / http://orcid.org/0000-0003-2580-2846 / erickalan23@gmail.com

PAULO RicARdo OpUSZKa Doutor em Direito pela Universidade Federal do Paraná (UFPR). Professor do Setor de Ciências Jurídicas da Universidade Federal do Paraná e Professor Colaborador do Mestrado em Direito Empresarial e Cidadania da Unicuritiba. Curitiba, Paraná, Brasil. http:// lattes.cnpq.br/2323335691144453 / http://orcid.org/0000-0003-3243-1000 / paulo.opuszka@gmail.com
\end{abstract}

\section{RESUMO}

Trata-se de resultados preliminares, integrantes de um amplo estudo em desenvolvimento, acerca da relação laboral e do instrumento utilizado para a sua implementação: o contrato de trabalho. Por meio da análise dos elementos do contrato de trabalho, problematiza-se e questiona-se a sua natureza jurídica, averiguando a existência dos requisitos necessários ao seu enquadramento como négocio juridico, proporcionando o entendimento da real viabilidade da afirmação de que o contrato de trabalho, efetivamente, pode ser considerado um contrato, ou seja, espécie de negócio jurídico. A pesquisa, também, sob a égide do Direito Capitalista do Trabalho, analisa os elementos fáticojurídicos da pessoalidade e da subordinação, observando suas atribuições na regulação e supressão de direitos. Do mesmo modo, observa os aspectos deste ramo do Direito que viabiliza o prosseguimento do modo de produção dominante, frisando a necessidade de cautela na implementação das reformas intentadas no ano de 2017 para a devida manutenção do estado atual da sociedade.
\end{abstract}

Palavras-chave: Direito Capitalista do trabalho; Pessoalidade; Subordinação.

\begin{abstract}
These are preliminary results, which are part of a large study under development, about the employment relationship and the instrument used for its implementation: the employment contract. Through the analysis of the elements of the labor contract, the legal nature of the contract is questioned and questioned, ascertaining the existence of the requisites necessary to its framework as legal business, providing an understanding of the real viability of the affirmation that the contract of employment, effectively, can be considered a contract, that is, kind of legal business. Research, also under the aegis of the Capitalist Labor Law, analyzes the factico-juridical elements of personnel and subordination, observing its attributions in the regulation and suppression of rights. In the same way, it observes the characteristics of this branch of law that makes possible the continuation of the dominant mode of
\end{abstract}


REFLEXÕES ENTRE REGULAÇÃO E A SUPRESSÃO DE DIREITOS A PARTIR DA PESSOALIDADE E SUBORDINAÇÃO NO DIREITO CAPITALISTA DO TRABALHO

production, stressing the need for caution in the implementation of the reforms introduced in 2017 for the proper maintenance of the current state of society.

Keywords: Capitalist Labour Law; Personnel; Subordination.

\section{RESUMEN}

Se trata de resultados preliminares, integrantes de un amplio estudio en desarrollo, acerca de la relación laboral y del instrumento utilizado para su implementación: el contrato de trabajo. A través del análisis de los elementos del contrato de trabajo, se problematiza y se cuestiona su naturaleza jurídica, averiguando la existencia de los requisitos necesarios para su encuadramiento como neto juridico, proporcionando el entendimiento de la real viabilidad de la afirmación de que el contrato de trabajo En efecto, puede ser considerado un contrato, o sea, especie de negocio jurídico. La investigación, también, bajo la égida del Derecho Capitalista del Trabajo, analiza los elementos fácticojurídicos de la personalidad y de la subordinación, observando sus atribuciones en la regulación y supresión de derechos. Del mismo modo, observa los aspectos de esta rama del Derecho que viabiliza la continuación del modo de producción dominante, subrayando la necesidad de cautela en la implementación de las reformas iniciadas en el año 2017 para el debido mantenimiento del estado actual de la sociedad.

Palabras clave: Derecho Capitalista del trabajo; Personalidad; Subordinación;

\section{SUMÁRIO}

INTRODUÇAO; 1 ELEMENTOS ESSENCIAIS, NATURAIS E ACIDENTAIS DO CONTRATO DE TRABALHO; 1.1 A inexistência de vontade livre e objeto lícito; 2 ELEMENTOS CARACTERIZADORES DA RELAÇÃO DE EMPREGO; 3 A LIBERDADE CONTRATUAL QUE APRISIONA O EMPREGADO E JUSTIFICA, LEGALMENTE, A SUA EXPLORAÇÃO; 4 SOBRE A PESSOALIDADE; 5 PROBLEMATIZANDO A SUBORDINAÇÃO; 5.1 Subordinação no direito capitalista do trabalho; CONCLUSÃO; REFERÊNCIAS.

\section{INTRODUÇÃO}

O presente artigo refere-se a apresentação de resultados preliminares, componentes de uma ampla pesquisa em progresso, a qual tem como objetivo o estudo dos elementos que compõem o contrato de trabalho, evidenciando-se as características que o individualizam, as quais vêm a preencher os requisitos necessários à sua caracterização como espécie de negócio jurídico.

Também, busca-se demonstrar que o Direito do Trabalho vem a ser um instrumento que regula e pacifica as relações existentes entre o capital e o trabalho, tornando-se fundamental para a manutenção do modo de produção.

Visando alcançar tal entendimento, através de análise bibliográfica, será realizado um panorama acerca do contrato de trabalho, ressaltando os elementos que trazem à tona e dão embasamento à destinação capitalista do Direito do Trabalho, assim, questionando dialeticamente os dogmas enraizados nos critérios que formam o contrato de trabalho. 
REFLEXÕES ENTRE REGULAÇÃO E A SUPRESSÃO DE DIREITOS A PARTIR DA PESSOALIDADE E SUBORDINAÇÃO NO DIREITO CAPITALISTA DO TRABALHO

Com intuito de ressaltar esta destinação, serão analisados os dois principais elementos fático-jurídicos ${ }^{1}$ da relação de emprego, a pessoalidade e a subordinação, critérios basilares ao Direito Capitalista do Trabalho.

O elemento fático-jurídico da pessoalidade tem relevância na análise empregada neste artigo em razão de provocar o questionamento acerca da viabilidade de negociação da força de trabalho como mercadoria.

O estudo da prestação intuitu personae delimitará as consequências dessa forma de prestação laboral, averiguando a existência de vantagens e desvantagens proporcionadas por esse modo de vínculo.

O enfoque na subordinação se dará por ser ela a responsável por submeter os indivíduos a respeitar e seguir o modo de produção estabelecido, fazendo com que os trabalhadores estejam vinculados às regras impostas pelo empregador e pelo Direito Capitalista do Trabalho.

A subordinação realça, através da imposição de regras estatais, apresentadas pelo Direito Capitalista do Trabalho, e pelos regulamentos internos criados pelos empregadores, a disparidade entre o empregador e os empregados, proporcionando a dupla exploração da mãode-obra através da apropriação da força de trabalho do empregado e mantendo-o como consumidor dos bens produzidos por ele, ocasionando, assim, que o modo de produção social dominante mantenha-se em pleno funcionamento, tendo o trabalhador como peça fundamental deste sistema: a produção e o consumo.

Também, por meio do estudo da liberdade contratual do empregado, questionar-se-á a verdadeira face dessa liberdade, evidenciando se, de fato, há liberdade ou apenas existe em caráter ficcional.

Assim, este artigo busca discutir os elementos insertos no Direito Capitalista do Trabalho, notando as discrepâncias e distorções por ele executadas nas relações de trabalho e o desequilíbrio que ele gera nestas, desequilíbrio que possui sempre o intuito de proteger e fortalecer o modo de produção social dominante.

\section{ELEMENTOS ESSENCIAIS, NATURAIS E ACIDENTAIS DO CONTRATO DE} TRABALHO

${ }^{1}$ DELGADO, Maurício Godinho. Curso de Direito do Trabalho. São Paulo: LTr, 2017, p.313. 
REFLEXÕES ENTRE REGULAÇÃO E A SUPRESSÃO DE DIREITOS A PARTIR DA PESSOALIDADE E SUBORDINAÇÃO NO DIREITO CAPITALISTA DO TRABALHO

Buscando um maior entendimento acerca do instrumento que viabiliza as relações de trabalho e, consequentemente, o Direito Capitalista do Trabalho, faz-se necessária a breve análise dos elementos que compõem este instrumento, o Contrato de Trabalho.

Ressalte-se que, em tópico posterior, serão expostas incongruências na definição da do contrato de trabalho como espécie de negócio jurídico. Porém, primeiramente, será realizada síntese dos elementos consagrados pela doutrina.

Conforme lição de Maurício Godinho Delgado “Os elementos componentes do contrato empregatício não diferem, em geral, daqueles já identificados pela teoria civilista clássica: trata-se dos elementos essenciais, naturais e acidentais do contrato."2.

Respeitadas as particularidades do Direito do Trabalho, conforme acima explanado, os elementos essenciais do Contrato de Trabalho seguem a teoria civilista clássica para a formação do contrato de trabalho, ou seja, deve-se observar a capacidade das partes contratantes, o objeto deve ser lícito e a forma deve ser prescrita ou não defesa em lei.

Frisa-se que o desrespeito a algum dos elementos essenciais acarretará a nulidade do contrato em questão.

Em relação à capacidade das partes, no Direito do Trabalho, conforme o Art. 402 da $\mathrm{CLT}^{3}$, a obtenção da capacidade plena para exercer atividades laborativas inicia-se aos dezoito anos de idade.

Porém, em consonância com a Constituição Federal, a partir dos quatorze anos de idade o jovem já cumpre o requisito etário mínimo para a celebração do contrato de trabalho, podendo ser contratado na condição de aprendiz.

Abstrai-se da leitura conjunta do Art. 402 da $\mathrm{CLT}^{4}$ e do Art. $7^{\circ}$, inciso XXXIII, da Constituição Federal $^{5}$, a existência da capacidade relativa para a atividade laboral, encontrada

\footnotetext{
2 DELGADO, Maurício Godinho. Curso de Direito do Trabalho. São Paulo: LTr, 2017, p.581.

${ }^{3}$ Art. 402. Considera-se menor para os efeitos desta Consolidação o trabalhador de quatorze até dezoito anos. In: BRASIL. Decreto-lei $n^{\circ} 5452$, de $1^{\circ}$ de maio de 1943. Consolidação das Leis do Trabalho. Disponível em: http://www.planalto.gov.br/ccivil_03/decreto-lei/Del5452.htm. Disponível em: 19 mai. 2017.

${ }^{4}$ Art. 403. É proibido qualquer trabalho a menores de dezesseis anos de idade, salvo na condição de aprendiz, a partir dos quatorze anos.In: BRASIL. Decreto-lei $n^{\circ} 5452$, de $1^{\circ}$ de maio de 1943 . Consolidação das Leis do Trabalho. Disponível em: http://www.planalto.gov.br/ccivil_03/decreto-lei/Del5452.htm. Disponível em: 19 mai. 2017.

5 Art. $7^{\circ}$ São direitos dos trabalhadores urbanos e rurais, além de outros que visem à melhoria de sua condição social: XXXIII - proibição de trabalho noturno, perigoso ou insalubre a menores de dezoito e de qualquer trabalho a menores de dezesseis anos, salvo na condição de aprendiz, a partir de quatorze anos.
} 
REFLEXÕES ENTRE REGULAÇÃO E A SUPRESSÃO DE DIREITOS A PARTIR DA PESSOALIDADE E SUBORDINAÇÃO NO DIREITO CAPITALISTA DO TRABALHO

no período que abrange os dezesseis anos até os dezoito anos de idade, faixa etária que necessita observar certas restrições na execução do contrato de trabalho, sendo as restrições que visam proteger o jovem as mais importantes, assim explana Maurício Godinho Delgado:

Existem, por fim, atos trabalhistas vedados ao trabalhador menor de 18 anos, ainda que relativamente capaz: é o que se passa, por exemplo, com a prestação laboral em período noturno ou em circunstâncias perigosas ou insalubres. ${ }^{6}$

De suma importância trazer a este artigo a advertência trazida por Maurício Godinho Delgado:

Esclareça-se que a cessação da incapacidade civil pela existência de relação empregatícia que assegure economia própria ao menor com 16 anos completos (art. $5^{\circ}$, parágrafo único, $\mathrm{V}, \mathrm{CCB} / 2002$ ) é dispositivo que não repercute no plano dos preceitos justrabalhistas examinados. Afinal, a diretriz civilista não invade o Direito do Trabalho na Seara em que este estabelece regras imperativas específicas em decorrência de fundamentos e objetivos próprios. ${ }^{7}$

Ou seja, apesar de respeitar diversos conceitos oriundos do Direito Civil, mostra-se salutar a imposição do Direito do Trabalho em afastar a possível afronta às proteções conferidas aos menores de dezoito anos por uma simples obtenção da capacidade plena na esfera Civilista.

Quanto à licitude do objeto no contrato de trabalho, a principal peculiaridade relativa a este elemento é a distinção existente entre trabalho ilícito e trabalho proibido.

Tem-se o trabalho proibido no momento em que a atividade laborativa é exercida em confronto a uma norma constante do ordenamento trabalhista, ou seja, apesar de o trabalho ser considerado lícito, a atividade ofende, por exemplo, alguma norma protetiva.

Já o trabalho ilícito é uma atividade enquadrada como ilícito penal, tendo suas consequências jurídicas direcionadas pelo Direito Penal, fugindo do alcance do Direito do Trabalho.

Essa distinção encontra respaldo na lição de Alice Monteiro de Barros:

Cumpre lembrar que a atividade ilícita não se confunde com a atividade proibida. $\mathrm{Na}$ primeira hipótese, o contrato não produz nenhum efeito, pois 'o negócio é reprovado pelo direito, em defesa dos interesses da sociedade, ou dos bons costumes e dos valores existentes'. Nesse caso, o 'valor tutelado é a realização

In: BRASIL. Constituição Federal. Brasília: Senado Federal, 1988. Disponível em: http://www.planalto.gov.br/ccivil_03/constituicao/constituicaocompilado.htm. Acesso em: 19 mai. 2017. ${ }^{6}$ DELGADO, Maurício Godinho. Curso de Direito do Trabalho. São Paulo: LTr, 2017, p.584.

${ }^{7}$ Ibidem. 
REFLEXÕES ENTRE REGULAÇÃO E A SUPRESSÃO DE DIREITOS A PARTIR DA PESSOALIDADE E SUBORDINAÇÃO NO DIREITO CAPITALISTA DO TRABALHO

da ordem pública'. Na segunda hipótese, isto é, na atividade proibida, o contrato produz certos efeitos e 'a tutela da ordem pública se realiza de modo mediato, prevalecendo 0 interesse do trabalhador ${ }^{8}$

Essa diferenciação repercute nos desdobramentos dos direitos trabalhistas, excluindo da proteção do Direito do Trabalho o trabalhador de atividade ilícita, porém os reconhecem ao trabalhador de atividade proibida, segundo Maurício Godinho Delgado:

O Direito do Trabalho tende a conferir efeitos justrabalhistas plenos à prestação empregatícia de trabalho irregular (ou trabalho proibido) - desde que a irregularidade não se confunda com um tipo legal criminal. A teoria justrabalhista de nulidades incide firmemente em tais situações, garantindo plenas consequências trabalhistas ao contrato maculado por irregularidade em seu objeto. Evidente que o reconhecimento de efeitos justrabalhistas não elimina a necessidade de determinar-se a correção do vício percebido ou extinguir-se o contrato, caso inviável semelhante correção. ${ }^{9}$

Por fim, resta analisar a instrumentalização do contrato de trabalho, a sua exteriorização, a qual deve guardar simetria às formas regulares ou não defesas em lei.

Conforme o Art. 107 do Código Civil $^{10}$, a forma preestabelecida para os contratos é excepcional, sendo regra o não-formalismo para esses pactos. O não-formalismo encontra espaço ainda maior principalmente no Direito do Trabalho o qual rege-se pelo Princípio da Primazia da Realidade, dando maior importância aos fatos ocorridos, deixando de lado os formalismos que poderiam ser aplicados para mascarar e desvirtuar a caracterização das relações de trabalho com a finalidade de reduzir gastos oriundos da legislação trabalhista.

Este posicionamento amplia a possibilidade de prova da existência de um contrato de trabalho, beneficiando o trabalhador ao reconhecer o contrato de trabalho sem a exigência de adstrição a elementos formais.

Em relação aos elementos naturais do contrato de trabalho que integram habitualmente o contrato de trabalho, temos como exemplo clássico a jornada de trabalho que, apesar de não ser essencial para a formação do contrato, mostra-se sempre inserta nas relações formadas.

Apesar de excepcionais, os elementos acidentais caracterizados pela doutrina civilista são encontrados nos contratos trabalhistas, explana desta forma Maurício Godinho Delgado:

\footnotetext{
${ }^{8}$ BARROS, Alice Monteiro de. Curso de Direito do Trabalho. São Paulo, LTr, 2016, p. 164.

${ }^{9}$ DELGADO, Maurício Godinho. Curso de Direito do Trabalho. São Paulo: LTr, 2017, p.586.

${ }^{10}$ Art. 107. A validade da declaração de vontade não dependerá de forma especial, senão quando a lei expressamente a exigir. In: BRASIL. Lei $n^{\circ}$ 10.406, de 10 de janeiro de 2002. Código Civil. Brasília, Disponivel em: http://www.planalto.gov.br/ccivil_03/leis/2002/L10406compilada.htm. Acesso em: 19 mai. 2017.
} 
REFLEXÕES ENTRE REGULAÇÃO E A SUPRESSÃO DE DIREITOS A PARTIR DA PESSOALIDADE E SUBORDINAÇÃO NO DIREITO CAPITALISTA DO TRABALHO

No Direito do Trabalho também o termo e a condição surgem como elementos acidentais do contrato empregatício, já que têm frequência francamente circunstancial e episódica no conjunto dos contratos celebrados. A existência e termo (certo ou incerto) nos contratos de trabalho é situação excetiva, viável apenas se configuradas hipóteses legais tipificadas e expressas (art.443 da CLT ou Lei $n^{\circ} 9601 / 98$, por exemplo). A regra geral incidente (e presumida) no cotidiano justrabalhista reporta-se aos contratos sem termo final prefixado. 0 tipo contratual dos pactos por tempo indeterminado considera-se presumido, caso não comprovada a lícita inserção de termo final no contrato em exame (súmula 212 do TST). ${ }^{11}$

Em que pese a importância dos elementos acima explanados, esses são analisados após a devida observância dos elementos que configuram a relação de emprego, os quais serão estudados posteriormente.

\subsection{A inexistência de vontade livre e objeto lícito}

Após preenchidos os elementos explanados acima, enfim convenciona-se a existência e validade do contrato, fundamentando a propagação das relações de emprego através do contrato de trabalho.

Porém, considerando que o contrato é uma espécie do gênero negócio jurídico, torna-se improvável considerar que o contrato de trabalho possa ser considerado, de fato, um contrato, tendo em vista a inexistência de vontade livre do empregado e o objeto ser ilícito no contrato de trabalho.

Há três correntes que objetivam conceituar o negócio jurídico, a voluntarista, a objetiva e a teoria da auto-responsabilidade. Todas buscam fundamentar o negócio jurídico através de alguma característica da vontade negocial.

Entretanto, na seara trabalhista, encontra óbice na própria vontade a caracterização do contrato de trabalho como espécie de negócio jurídico, apesar da ampla maioria da doutrina indicar a relação laboral como sendo contratual:

Pensamos que o vínculo entre empregado e empregador é uma relação jurídica de natureza contratual. Nínguem será empregado de outrem senão por sua própria vontade. Assim, mesmo que uma pessoa comece a trabalhar para outra sem que expressamente nada tenha sido combinado entre ambas, isso só será

${ }^{11}$ DELGADO, Maurício Godinho. Curso de Direito do Trabalho. São Paulo: LTr, 2017, p.591. 
REFLEXÕES ENTRE REGULAÇÃO E A SUPRESSÃO DE DIREITOS A PARTIR DA PESSOALIDADE E SUBORDINAÇÃO NO DIREITO CAPITALISTA DO TRABALHO

possivel pela vontade ou pelo interessa das duas. ${ }^{12}$

A afirmação que o empregado possui autonomia para livremente tomar as diretrizes de sua vida em relação aos empregos que irá aceitar, principalmente em momentos de crise, demonstra-se totalmente inadequada à realidade, como bem explanado por Eduardo Milléo Baracat:

Quando se lê nos manuais de Direito do Trabalho que o trabalhador tem liberdade para aceitar ou não determinado emprego, conforme sua livre e espontânea vontade, está-se a falar do mundo do dever-ser, e não do mundo real brasileiro. ${ }^{13}$

Do mesmo modo, Alain Supiot refuta a ideia da autonomia da vontade do empregado "A única liberdade -que não se pode negligenciar- do trabalhador num tal quadro jurídico é a liberdade de escolher o empregador a quem se subordinar[...]" ${ }^{\prime 14}$, reforçando a inconsistência da afirmação que estipula a existência de livre vontade do empregado.

Juntamente com o impedimento da vontade, o objeto ilícito se faz presente no contrato de trabalho.

Impossível desvincular a força de trabalho do próprio trabalhador, o contrato de trabalho, em relação ao produto que dispõe no mercado de trabalho, "contradiz a separação entre pessoas e coisas que funda a ordem do comércio"15, causa aversão a ideia da possibilidade de dispor de seres humanos através de atos contratuais, porém é o que ocorre, na realidade, por meio do contrato de trabalho.

Ou seja, o corpo humano tem inegável papel na prestação objeto do contrato de trabalho, questiona Alain Supiot:

Não podendo ser assimilado a uma coisa, o corpo humano está, pelo mesmo título que a pessoa, fora do comércio, o que fere de nulidade toda a convenção de que seja objecto. Assente este princípio - e devendo ser defendida a opção valorativa de que ele procede -, como conciliá-lo com a licitude do contrato de trabalho? ${ }^{16}$

A fim de tornar possível a comercialização da mão-de-obra, retira-se do corpo humano o

\footnotetext{
${ }^{12}$ NASCIMENTO, Amauri Mascaro, Iniciação ao Direito do Trabalho. São Paulo, LTr, 2009, p. 150.

${ }^{13}$ BARACAT, Eduardo Milléo. A boa-fé no direito individual do trabalho. São Paulo, LTr, 2003, p. 115.

${ }^{14}$ SUPIOT, Alain. Crítica do Direito do Trabalho. Lisboa, Fundação Calouste Gulbenkian, 2016. p. 155.

${ }^{15}$ SUPIOT, Alain. Homo Juridicus: ensaio sobre a função antropológica do Direito $1^{\mathrm{a}} \mathrm{ed}$. Lisboa: Instituto Piaget, 2005, p. 123.

${ }^{16}$ SUPIOT, Alain. Crítica do Direito do Trabalho. Lisboa, Fundação Calouste Gulbenkian, 2016. p. 76.
} 
REFLEXÕES ENTRE REGULAÇÃO E A SUPRESSÃO DE DIREITOS A PARTIR DA PESSOALIDADE E SUBORDINAÇÃO NO DIREITO CAPITALISTA DO TRABALHO

produto que será comercializado no mercado de trabalho, a força de trabalho vem a ser abstraída do corpo humano, viabilizando a contraprestação pecuniária.

Entretanto, o contrato de trabalho continua, substancialmente, não se configurando espécie de negócio jurídico, apenas o sendo através de um acordo pragmático.

\section{ELEMENTOS CARACTERIZADORES DA RELAÇÃO DE EMPREGO}

A relação de emprego caracteriza-se a partir dos seguintes elementos: trabalho prestado por pessoa física, com pessoalidade por parte do trabalhador, de forma subordinada, não-eventual e prestada com onerosidade.

Assim, para que a relação jurídica esteja sob o espectro do Direito do Trabalho, a prestação de serviços deve ser realizada por uma pessoa física, ou seja, pessoa natural.

Porém, com o objetivo de evitar fraudes, é possível a caracterização deste elemento mesmo quando o trabalho é prestado aparentemente por uma pessoa jurídica, a famigerada “Pejotização”, conforme Maurício Godinho Delgado “Demonstrado, pelo exame concreto da situação examinada, que o serviço diz respeito apenas e tão somente a uma pessoa física, surge o primeiro elemento fático-jurídico da relação empregatícia”"17.

A pessoalidade ocorre apenas por parte do empregado, sendo a sua prestação de serviço considerada infungível, não podendo, em regra, fazer-se substituir por outrem, assim explana Alice Monteiro de Barros "O pressuposto da pessoalidade exige que o empregado execute suas atividades pessoalmente, sem se fazer substituir, a não ser em caráter esporádico, com a aquiescência do empregador"18.

No tocante à não-eventualidade, abstraindo as polêmicas que envolvem este elemento da relação de emprego, este caracteriza-se, basicamente, como o trabalho prestado de forma não esporádica, conforme leciona Maurício Godinho Delgado "se a prestação é descontínua, mas permanente, deixa de haver eventualidade"19. Ou seja, para cumprir o elemento da nãoeventualidade a prestação de serviços deve ocorrer de modo permanente, não importando se ocorre de modo descontínuo.

\footnotetext{
${ }^{17}$ DELGADO, Maurício Godinho. Curso de Direito do Trabalho. São Paulo: LTr, 2017, p.315.

${ }^{18}$ BARROS, Alice Monteiro de. Curso de Direito do Trabalho. São Paulo, LTr, 2016.p. 174.

19 DELGADO, Maurício Godinho. Curso de Direito do Trabalho. São Paulo: LTr, 2017, p.320.
} 
REFLEXÕES ENTRE REGULAÇÃO E A SUPRESSÃO DE DIREITOS A PARTIR DA PESSOALIDADE E SUBORDINAÇÃO NO DIREITO CAPITALISTA DO TRABALHO

Por estar inserto no sistema capitalista, a relação de emprego, claramente, necessita do elemento onerosidade, pois desta forma insere o empregado no universo do capital, fazendo com que o mesmo possa consumir os bens produzidos pelos trabalhadores.

Concluindo os elementos formadores da relação de emprego, o mais singular dentre eles, a subordinação, deve ser encontrada de forma obrigatória na relação jurídica para que se possa caracterizá-la como relação empregatícia que será regulada pelo Direito do Trabalho.

Este último elemento, juntamente com o elemento da pessoalidade, será destrinchado em tópico futuro neste artigo.

\section{A LIBERDADE CONTRATUAL QUE APRISIONA O EMPREGADO E JUSTIFICA, JURIDICAMENTE, SUA EXPLORAÇÃO}

O contrato de trabalho e a liberdade conferida ao empregado de negociar no mercado de trabalho podem ser interpretados, quanto ao seu benefício, de maneiras, entre si, contraditórias.

Bom, primeiramente, o contrato de trabalho tem o mérito de estabelecer uma relação entre sujeitos alheios a qualquer relação preestabelecida de posse, ou seja, o contrato de trabalho seria um avanço para a própria dignidade humana em comparação à servidão e à escravidão.

Entretanto, também se interpreta essa liberdade como ilusória, devido as partes contratantes não estarem no mesmo patamar de força, os contratos de trabalho tornam-se meros contratos de adesão que rechaçam a possibilidade de mínima barganha por parte do empregado.

Fato constatado em 1944 por Orlando Gomes:

o contrato de trabalho convertera-se em ato de adesão do trabalhador a condições impostas discricionariamente pela outra parte. Para impedir que as massas sofressem os efeitos dessa escravização, a lei conferiu aos trabalhadores certos direitos, prerrogativas e vantagens, as quais figuram, nos quadros do civilismo, como restrições à liberdade de estipulação do conteúdo da relação de trabalho ${ }^{20}$

20 GOMES, Orlando apud RAMOS FILHO, Wilson. Direito Capitalista do Trabalho: História, Mitos e Perspectivas no Brasil. São Paulo: LTr, 2012, p.24. 
REFLEXÕES ENTRE REGULAÇÃO E A SUPRESSÃO DE DIREITOS A PARTIR DA PESSOALIDADE E SUBORDINAÇÃO NO DIREITO CAPITALISTA DO TRABALHO

E, como adverte Huberman, a submissão a estas imposições ocorre no momento em que certas condições desvantajosas para o empregado são identificadas:

Somente quando os trabalhadores não são donos da terra e das ferramentas somente quando foram separados desses meios de produção- é que procuram trabalhar para outra pessoa. Não o fazem por gosto, mas porque são obrigados, a fim de conseguir recursos para comprar alimentos, roupa e abrigo, de que necessitam para viver. Destituídos dos meios de produção, não têm escolha. Devem vender a única coisa que lhes resta - sua capacidade de trabalho, sua força de trabalho. ${ }^{21}$

Paul Singer, ao comentar sobre a teoria do valor-trabalho ${ }^{22}$, proporciona o entendimento de que os novos meios de imposição ao desempenho de atividades produtivas deixou de priorizar a coação física, proveniente da escravidão, para estabelecer um modo de coação social:

Essas regras permitem aos donos das empresas acumular capital que repõem os meios de produção desgastados e amplia a capacidade da produção. A segunda função dessas regras é dar a ilusão às pessoas de que elas estão nisso voluntariamente. 0 que é muito importante. Em outros modos de produção, como a servidão ou a escravidão, o trabalho é forçado, isto é, só se extrai mais trabalho da pessoa se você a submete fisicamente e the impõe essa carga. No sistema capitalista, há um tal conjunto de regras sociais, que ninguém pode dizer que está obrigado. Na verdade, o proletário está obrigado porque se não trabalhar, não ganhar salário, morre de fome. Mas, em princípio, e isso é uma ilusão necessária de que todos compartilham, cada um se insere na economia por livre escolha. ${ }^{23}$

No momento do Estado Liberal, este apenas orbitava as relações estabelecidas entre os empregadores e empregados, respeitando a liberdade formal dos sujeitos, regendo-se sob a égide do direito civil de modo a tratar este vínculo como uma mera relação entre sujeitos privados.

Este ambiente de liberdade contratual gerava a ilusão da existência de "colaboração entre seres livres e iguais" fazendo com que "sob a aparência de uma relação comutativa se

\footnotetext{
${ }^{21}$ HUBERMAN, Leo. História da riqueza do homem. Rio de janeiro, Zahar, 1984, p. 175.

22 Trata-se de teoria econômica associada, principalmente, a Adam Smith, a qual defende que em última análise o valor das mercadorias é consubstanciando por apenas um determinado custo, que vem a ser o trabalho humano.

${ }^{23}$ SINGER, PAUL. Aprender Economia. São Paulo, Brasiliense, 1988, p. 37.
} 
REFLEXÕES ENTRE REGULAÇÃO E A SUPRESSÃO DE DIREITOS A PARTIR DA PESSOALIDADE E SUBORDINAÇÃO NO DIREITO CAPITALISTA DO TRABALHO

ERICK ALAN DE LIMA PAULO RICARDO OPUSZKA

operava a magia do contrato, ocultado a realidade conflitiva, desigual e injusta dessa relação." ${ }^{24}$.

O aparente ganho à dignidade humana ao conceder liberdade aos sujeitos contratuais desaparece no momento em que esta liberdade não gera benefícios efetivos aos trabalhadores e desvirtua o Estado do seu real objetivo, como bem ilustra Maíra Silva Marques da Fonseca:

Diante dos maiores abusos dos fortes contra os fracos, viu-se anulada a tão almejada liberdade. 0 Estado, mais do que simples assistente dos acontecimentos, passou a ser, sob o domínio do capitalismo liberal, um instrumento de opressão contra os menos favorecidos, afastando-se de sua missão de fazer inseparáveis o bem individual e o bem coletivo, negligenciando os interesses da sociedade. ${ }^{25}$

Neste sentido, Arion Sayão Romita possui o posicionamento de que esta liberdade se tornou fonte de exploração do trabalhador por não respeitar as desigualdades materiais encontradas no campo social entre os detentores dos meios de produção e o empregado:

\begin{abstract}
a liberdade jurídico-formal de contratar constituiu, para o trabalhador, fonte de exploração. A igualdade jurídica não refletia a desigualdade social e econômica entre o trabalhador e o detentor dos meios de produção. 0 sistema de liberdade contratual limita as relações entre empregado e empregador aos deveres contratuais mútuos, prescindindo de um fundo ético-social; vê na relação de trabalho unicamente troca de bens patrimoniais, que considera homogêneos: trabalho e salário. Desconhece que o trabalho não é um bem patrimonial como os demais, pois não se destaca da personalidade humana ${ }^{26}$
\end{abstract}

Em meio a este ambiente de desigualdade social, observa-se que a única liberdade experimentada pelo trabalhador seria a liberdade de escolher para qual empregador ele seria subordinado, de todo modo, essa escolha apenas seria possível em condições que o mercado de trabalho estivesse em uma plenitude utópica.

Assim, resta ao empregado, tendo em vista que possui apenas um bem negociável, a sua força de trabalho, a qual restringe quase que totalmente as suas opções de escolha, submeter-se ao empregador que o aceite e através do contrato de trabalho celebrar esta farsa que é a sua liberdade de contratar.

\footnotetext{
${ }^{24}$ RAMOS FILHO, Wilson. Direito Capitalista do Trabalho: História, Mitos e Perspectivas no Brasil. São Paulo: LTr, 2012, p.24.

${ }^{25}$ MARQUES DA FONSECA, Maíra Silva. Redução Da Jornada De Trabalho A Partir Da Análise Do Sistema Capitalista De Produção: Fundamentos Interdisciplinares. 2011. Disponível em: http:/ / acervodigital.ufpr.br/bitstream/handle/1884/25554/DISSERTACAO\%20\%20Maira\%20S\%20M\%20Fonseca.pdf?sequence=1. Acesso em: 19 mai. 2017. p. 80.

${ }^{26}$ ROMITA, Arion Sayão. A subordinação no contrato de trabalho. Rio de Janeiro, Forense, 1979. p. 12.
} 

juridicamente, o liberalismo econômico:

Ao assegurar aos sujeitos a possibilidade de regular por si próprios as ações ou permitir que determinem as regras de comportamento comum através da vontade e do consenso, segundo seus interesses, a ordem normativa sob o discurso da liberdade jurídica permitiu mascarar o liberalismo econômico sob o disfarce jurídico e acarretou uma nova forma dissimulada de exploração dos mais fracos economicamente[.... $]^{27}$

Enfim, esta liberdade distorce a relação de trabalho, a encara como uma pura relação sinalagmática em que julga como equivalentes as prestações estabelecidas no contrato de trabalho, o que não ocorre por conta da mais-valia aplicada pelo empregador, e desconsidera a impossibilidade de desmembrar a força de trabalho do próprio trabalhador, gerando, novamente, uma crítica aos que defendem a liberdade contratual como um ganho à dignidade humana, pois esta utiliza-se de um campo fático desfavorável a um dos contraentes, o empregado, para, no fim, mercantilizar o próprio ser humano.

\section{SOBRE A PESSOALIDADE}

A discussão acerca da pessoalidade no Direito Capitalista do Trabalho diz respeito ao modo como o trabalho é encarado, sendo este visto como uma mera mercadoria inserida no processo produtivo capitalista, tornando o empregado uma simples mercadoria. No entanto, questiona-se a possibilidade desta ficção ocorrer, tendo em vista a impossibilidade de desvinculação da força de trabalho da própria pessoa devedora.

Segundo Alain Supiot, esta ficção é necessária para assegurar o bom funcionamento do mercado, porém, conjuntamente, deve-se manter um estatuto que impeça a objetificação do ser humano:

Estas ficções são artefactos jurídicos, porque é o Direito que autoriza, por exemplo que se aja como se o trabalho fosse mercadoria separável da pessoa do

\footnotetext{
${ }^{27}$ COUTINHO, Aldacy Rachid. Função social do contrato individual de trabalho. In COUTINHO, Aldacy Rachid et alii [Coord.]. Transformações do Direito do Trabalho. Estudos em homenagem ao Professor Doutor João Regis Fassbender Teixeira. Curitiba, Juruá, 2000, p. 31.
} 
REFLEXÕES ENTRE REGULAÇÃO E A SUPRESSÃO DE DIREITOS A PARTIR DA PESSOALIDADE E SUBORDINAÇÃO NO DIREITO CAPITALISTA DO TRABALHO

trabalhador, organizando um estatuto salarial que delimita essa mercantilização e impede que se trate o homem como coisa. ${ }^{28}$

Ao tratar do estudo do poder disciplinar do empregador, Arion Sayão Romita analisa as características do poder diretivo sob seus aspectos subjetivos decorrentes da relação de trabalho, considerando que:

O trabalho é inseparável da pessoa daquele que o presta. A subordinação do trabalhador integrado na organização empresarial e o consequente poder de disposição que o credor de trabalho assume em face da atividade do obreiro salientam o caráter pessoal da relação de trabalho. 0 aspecto subjetivo e o objetivo não podem ser, portanto, isolados um do outro. Ao revés, geram um todo inseparável, que revela uma só realidade: o caráter pessoal-patrimonial da relação de trabalho subordinado. ${ }^{29}$

Assim, demonstra que o elemento da pessoalidade na relação de trabalho classifica-se como um dos seus maiores caracterizadores, não ocorrendo apenas em situações pontuais e excepcionais, por exemplo, nos casos de substituição autorizadas pela legislação.

A corrente liberal ${ }^{30}$, com o intuito de viabilizar a contratação da força de trabalho, utilizou-se do conceito de locação de serviços do direito romano, encarando que a contratação ocorre entre indivíduos formalmente iguais, porém encara a força de trabalho como uma mercadoria destacável da pessoa do trabalhador, entendendo que o trabalhador seria apenas um negociador deste produto.

Desta forma, busca superar o caráter não-patrimonial do corpo, deturpando o papel essencial que o corpo do trabalhador representa nesta relação jurídica, tendo em vista que a pessoa, sem dúvida, é além de um dos sujeitos contratantes o próprio objeto que passa a ser negociado e contratado.

Ou seja, analisando os objetos das obrigações do contrato de trabalho estes dividem-se, conforme a doutrina clássica, pelo pagamento do salário pelo empregador e pela prestação do trabalho pelo empregado. Ao constatar que o físico do trabalhador é indissociável da sua

\footnotetext{
${ }^{28}$ SUPIOT, Alain. Homo Juridicus: ensaio sobre a função antropológica do Direito $1^{\text {a } e d . ~ L i s b o a: ~ I n s t i t u t o ~}$ Piaget, 2005, p. 119.

${ }^{29}$ ROMITA, Arion Sayão. 0 poder disciplinar do empregador. Rio de Janeiro, Biblioteca Jurídica Freitas Bastos, 1983. p. 38.

${ }^{30}$ Corrente de pensamento, originada no século XVII, a qual defende o progresso econômico através da existência de um livre mercado, ausente de tarifas e barreiras econômicas protecionistas, encara todos os cidadãos como sujeitos que possuem direitos iguais e que necessitariam apenas do seu próprio esforço e dedicação às atividades econômicas para galgar posições sociais superiores.
} 
REFLEXÕES ENTRE REGULAÇÃO E A SUPRESSÃO DE DIREITOS A PARTIR DA PESSOALIDADE E SUBORDINAÇÃO NO DIREITO CAPITALISTA DO TRABALHO

ERICK ALAN DE LIMA PAULO RICARDO OPUSZKA

obrigação, pode-se afirmar que nesta relação o próprio homem passa a ser tratado como uma mercadoria.

Em que pese tais distorções, este importante elemento nos concede a oportunidade de buscar a defesa do indivíduo trabalhador, pois ao reconhecer o caráter intuito personae da relação de trabalho pode-se buscar, conforme Raphaela Magnino Rosa Portilho a qual analisa a obra de Alain Supiot, o equilíbrio dos riscos inerentes à relação de trabalho:

\begin{abstract}
Em uma relação de trabalho, tem-se que o empregador arrisca seu patrimônio enquanto o trabalhador arrisca sua saúde. Assim, tudo aquilo capaz de afetar o corpo (idade, sexo, maternidade, doença, etc.), objeto do contrato de trabalho, afeta necessariamente o contrato. Daí decorre a noção de que o objeto só pode ser lícito se consistir em um corpo apto ao trabalho. Dessa forma, a inaptidão priva o contrato de um objeto lícito, levando à sua ruptura ou à redefinição dos termos. No que tange ao aspecto da segurança para o trabalho, tem-se um contexto de segurança econômica. Não se pode considerar suficiente que o trabalhador saia fisicamente incólume após prestar seu trabalho, também é necessário que ele possua meios de perpetuar sua força de trabalho e de manter sua família. A concepção puramente contratual da relação de trabalho seria incapaz de prover essa segurança aos trabalhadores, à medida que imputaria todos os riscos da atividade ao trabalhador, que teria na força de trabalho parte de seu patrimônio. ${ }^{31}$
\end{abstract}

Assim, o elemento da pessoalidade possibilitou a humanização da relação de trabalho, demonstrando o caráter desproporcional do risco suportado pelo trabalhador com o seu próprio corpo, diferente do simples risco econômico enfrentado pelo empregador.

Entretanto, este reconhecimento da pessoa humana como objeto central da contratação laboral não se deu apenas pela bondade dos empregadores ou do próprio Estado, todos os direitos decorrentes da pessoalidade que buscam a proteção pessoal do trabalhador possuem, em sua essência, a intenção de proteger o mecanismo capitalista de produção.

Ora, não se pode negar que o empregador se beneficia de todos os direitos decorrentes do reconhecimento da pessoalidade do trabalhador, o empregador necessita da mão-de-obra saudável e com um mínimo de repouso para desempenhar as suas atividades, também necessita que a massa de trabalhadores e consumidores se reproduzam, decorrendo disto as proteções concedidas como, por exemplo, as férias, limitação de jornada e proteções à maternidade.

${ }^{31}$ PORTILHO, Raphaela Magnino Rosa. O Direito do Trabalho na Visão Crítica de Alain Supiot. 2014. Disponível em: http://www.publicadireito.com.br/artigos/?cod=092cb9ab3aaf99bd. Acesso em: 19 mai. 2017. p. 9. 
REFLEXÕES ENTRE REGULAÇÃO E A SUPRESSÃO DE DIREITOS A PARTIR DA PESSOALIDADE E SUBORDINAÇÃO NO DIREITO CAPITALISTA DO TRABALHO

Em razão disso, a reforma trabalhista, a ser implementada no Brasil, é, simplesmente, o Estado e o Empregador serrando, juntos, o galho no qual estão sentados, pois, considerando os possíveis malefícios trazidos à produtividade e saúde do trabalhador, haverá, de modo reflexo, impacto negativo na economia, comércio e previdência.

Até mesmo as discussões relativas ao estabelecimento de um salário mínimo decorreram, inicialmente, da necessidade de manutenção dos trabalhadores, buscando conceder-lhes apenas o mínimo existencial para a sua contínua reprodução, como descreve Alain Supiot acerca da utilização da "lei de bronze dos salários” nas discussões para a implementação de um salário mínimo para os trabalhadores:

A noção de mínimo vital que inspirou as primeiras leis sobre o salário não estava muito distante da 'lei de bronze dos salários' que os economistas julgavam ter descoberto, pois conduz a garantir juridicamente a perpetuação da força de trabalho, a que tenderia naturalmente a lei do mercado. Mas, desse mínimo vital, passou-se depressa à ideia de um salário 'decente' ou 'suficiente, isto é, indexado já não apenas às exigências biológicas da reprodução da força de trabalho, mas às exigências sociais resultantes do estado geral de riqueza da sociedade a que pertence o trabalhador. ${ }^{32}$

Abstrai-se desse fragmento de Alain Supiot a tênue passagem de um pensamento simplista de proteção à procriação do trabalhador, para a observação do trabalhador como, também, um consumidor em potencial das riquezas produzidas por ele próprio.

Outra consequência da pessoalidade inserida no campo do Direito Capitalista do Trabalho é a própria individualização do empregado, o qual conquista a sua individualidade perante o coletivo, porém o reconhecimento de direitos individuais do trabalhador, os quais transitam desde os direitos do trabalhador sobre a obra por ele criada até as negociações decorrentes da autonomia do trabalhador qualificado para exigir e negociar alterações no seu ambiente laboral, podem trazer aos trabalhadores menos qualificados um risco inerente a essa desvinculação do plano coletivo, o qual, agravado pelo enfraquecimento do sindicalismo, gerará uma desproteção dos indivíduos que encontravam seus direitos resguardados no campo coletivo pelo sindicato ou até mesmo pelo Estado.

Deste modo, adverte Alain Supiot acerca das consequências dessa individualização do trabalhador e do enfraquecimento da esfera coletiva no âmbito laboral:

\footnotetext{
${ }^{32}$ SUPIOT, Alain. Crítica do Direito do Trabalho. Lisboa, Fundação Calouste Gulbenkian, 2016. p. 103.
} 
REFLEXÕES ENTRE REGULAÇÃO E A SUPRESSÃO DE DIREITOS A PARTIR DA PESSOALIDADE E SUBORDINAÇÃO NO DIREITO CAPITALISTA DO TRABALHO

Enquanto a definição colectiva das regras sobre a relação de trabalho dava a cada trabalhador títulos jurídicos oponíveis ao poder patronal e o inseria numa comunidade de direitos e de interesses, a individualização reduzir-se-ia a um desmantelamento desses direitos enraizados no colectivo, isto é, em fim das contas a uma de-subjectivação dos assalariados. A terra prometida do indivíduo dono do seu destino só será, com efeito, acessível ao pequeno número de trabalhadores capazes de darem um conteúdo concreto aos direitos individuais. Para todos os outros, o refluxo das protecções colectivas deixará espaço livre a novas formas de normalização e de exploração (dentro e fora da empresa). ${ }^{33}$

O elemento da pessoalidade, do mesmo modo que o Direito do Trabalho, mostra-se ambivalente, de um lado dando substrato às conquistas relativas às inúmeras proteções concedidas à pessoa do trabalhador, de outro lado traz o risco de, ao individualizar o empregado, reduzir os direitos conquistados no campo coletivo, prejudicando os trabalhadores menos qualificados, os quais não possuem espaço para buscar a negociação dos seus direitos e responsabilidades perante o seu empregador.

\section{PROBLEMATIZANDO A SUBORDINAÇÃO}

Primeiramente, deve-se frisar que os elementos da pessoalidade e da subordinação caminham entrelaçados nas relações empregatícias, tendo seu surgimento e embasamento no contrato de trabalho.

Tal característica não passou despercebida pelo doutrinador Arion Sayão Romita, o qual traz à tona as qualidades contratuais da subordinação e converge à aceitação de que a subordinação não se pauta em uma situação de hierarquia, mas sim em uma relação entre credores e devedores:

No Direito do Trabalho, a subordinação tem origem contratual. Seu caráter pessoal se conjuga com o elemento patrimonial, que deriva da retribuição do trabalho ante a onerosidade ínsita ao contrato de emprego. Os dois elementos pessoal e patrimonial - são, portanto, inseparáveis, e encontram explicação no contrato. À obrigação de obediência do empregado, a doutrina hoje atribui conteúdo e fundamento contratual: ao estipular o contrato de trabalho, o empregado obriga-se a seguir as instruções emitidas pelo empregador. Por tal motivo, este comanda não como chefe ou hierarca, mas como credor; o empregado deve obedecer não como inferior, mas porque, ao celebrar livremente o contrato, prometeu obedecer. A subordinação não deve ser

\footnotetext{
${ }^{33}$ SUPIOT, Alain. Crítica do Direito do Trabalho. Lisboa, Fundação Calouste Gulbenkian, 2016. p. 103.
} 
REFLEXÕES ENTRE REGULAÇÃO E A SUPRESSÃO DE DIREITOS A PARTIR DA PESSOALIDADE E SUBORDINAÇÃO NO DIREITO CAPITALISTA DO TRABALHO

entendida como potestade exercida por um superior sobre um inferior hierárquico, mas como poder de um credor para com um devedor, contratualmente acertado entre as partes. ${ }^{34}$

Os estudos que abordaram o tema da subordinação nas relações de trabalho observaram-no sempre por diversas perspectivas com o objetivo de justificar a existência da subordinação, fundamentando-a de maneiras diversas buscando uma melhor compreensão deste elemento.

A doutrina observa três principais critérios para caracterizar a subordinação, podendo ela ser vista sob a perspectiva da dependência técnica, econômica e da subordinação jurídica.

No momento histórico em que o empregador era o detentor total das técnicas aplicadas ao processo produtivo, acreditava-se que a subordinação ocorria através da dependência técnica por parte do empregado, o que, definitivamente, não ocorre na moderna empresa onde o empregador possui, em geral, apenas a incumbência da gestão da produção, não sendo necessário que o empregador detenha o conhecimento amplo da técnica aplicada à produção da empresa.

Observa-se, assim, que a dependência técnica se tornou insuficiente para a caracterização da subordinação.

Quanto ao critério da dependência econômica, ao generalizar as relações de emprego, buscando sua fundamentação em um critério alheio ao campo jurídico, fragiliza-se como caracterizador da subordinação.

Em que pese a grande maioria dos empregados realmente necessitar e serem dependentes economicamente dos seus empregos, este critério pode muito bem não ser encontrado em certos contratos de trabalho em que o empregado possui plenas condições econômicas, as quais o excluem da dependência econômica junto ao empregador.

Ou seja, a existência de um contrato de trabalho sem a dependência econômica é plenamente possível, não descaracterizando a relação de emprego apenas pela inexistência de tal dependência.

Atualmente, a subordinação jurídica é amplamente aceita pela doutrina. Entende-se como uma subordinação que deriva estritamente do Direito, libertando o conceito da subordinação de critérios socioeconômicos e técnicos, em que o empregado através de um

\footnotetext{
${ }^{34}$ ROMITA, Arion Sayão. A subordinação no contrato de trabalho. Rio de Janeiro, Forense, 1979. p. 98.
} 
REFLEXÕES ENTRE REGULAÇÃO E A SUPRESSÃO DE DIREITOS A PARTIR DA PESSOALIDADE E SUBORDINAÇÃO NO DIREITO CAPITALISTA DO TRABALHO

contrato de trabalho vincula-se ao empregador, estabelecendo uma relação jurídica entre os sujeitos contratantes.

Deste contrato irradiam diversos direitos para ambas as partes, sendo que ao empregador resta o poder diretivo, o qual torna possível a imposição de diversos ordenamentos ao empregado subordinando-o ao empregador e às suas intenções pré-acordadas ou não.

\title{
5.1 Subordinação no direito capitalista do trabalho
}

Pois bem, passando ao Direito Capitalista do Trabalho, observa-se que a subordinação vem a ser um dos maiores aspectos caracterizadores deste ramo do Direito.

Ao discutir acerca deste ramo, desprende-se da rasa argumentação de que o Direito do trabalho visa apenas a proteção do trabalhador em detrimento do empresário capitalista, conforme já indicava há muito Bernard Edelman em seu livro "A Legalização da Classe Operária”, não reconhecendo a existência do Direito do Trabalho livre de influências das concepções do Direito Burguês:

\begin{abstract}
Devemos nos livrar de uma vez por todas da ilusão tenaz de um 'direito operário' que manteria distância do direito burguês, que seria um tubo de ensaio em que se elaboraria um 'novo direito'. Tradicionalmente, os especialistas têm empregado seus esforços nesse sentido. É necessário, dizem esses especialistas, autonomizar o direito do trabalho, dar-lhe seus títulos, reconhecer sua especificidade. Ele é, continuam eles, um direito coletivo, um direito de massa, para as massas, que já não tem nada- ou tem cada vez menos- a ver com o direito 'comum', leia-se, o direito civil. Desse esforço nasceu 'o socialismo dos juristas', que se perpetua até hoje sob as espécies sutis e técnicas das relações entre direitos: direito do trabalho/direito civil, direito do trabalho/direito comercial, direito do trabalho/direito público... Como se o trabalho estivesse 'do lado' do capital e do Estado! Como se o 'direito operário' não fosse o direito burguês para o operário! $\mathrm{E}$ como se, enfim, milagrosamente, o direito do trabalho fosse uma zona juridicamente 'protegida'! Não existe o 'direito do trabalho'; existe um direito burguês que se ajusta ao trabalho, ponto-final. ${ }^{35}$
\end{abstract}

Evidente a necessária utilização do Direito do Trabalho pelo sistema capitalista, o qual acaba moldando as práticas dos trabalhadores ao Direito, dirigindo-as, legalmente, conforme o interesse do capital.

Também, sabe-se que o Direito Capitalista do Trabalho utiliza de meios para garantir, por meio de benesses aos trabalhadores, um ambiente pacífico e, assim, propício à produção

\footnotetext{
${ }^{35}$ EDELMAN, Bernard. A legalização da Classe Operária. São Paulo, Boitempo, 2016. p. 19.
} 
REFLEXÕES ENTRE REGULAÇÃO E A SUPRESSÃO DE DIREITOS A PARTIR DA PESSOALIDADE E SUBORDINAÇÃO NO DIREITO CAPITALISTA DO TRABALHO

ERICK ALAN DE LIMA PAULO RICARDO OPUSZKA

capitalista. Por meio deste mecanismo, a subordinação ao empregador passa a ser justificada pelo Direito Capitalista do Trabalho.

A intenção de buscar justificativa à subordinação é feita com maestria pelo Direito Capitalista do Trabalho, pois este traz o Estado à luta por essa pacificação dos trabalhadores, judicializando as discussões sobre os conflitos trabalhistas, conforme Wilson Ramos Filho afirma:

Assim, a principal função do Direito do Trabalho, sua razão de ser como ramo específico da ordem jurídica, portanto, consiste em servir ao processo de juridicização do conflito entre trabalho assalariado e capital, com a integração ou institucionalização desse conflito pelo Estado. ${ }^{36}$

Dessa forma, o Direito Capitalista do Trabalho, ao integrar o Estado nos conflitos trabalhistas, concede ao próprio Estado mais uma ferramenta de intervenção no cenário produtivo, possibilitando que através deste Direito opere certas incisões para a manutenção da saúde do sistema capitalista.

A subordinação na relação de trabalho cumpre papel de grande importância para a manutenção de toda a ordem capitalista de produção, ela vem a ser o atributo que possibilita o alcance individual das diretrizes capitalistas, permitindo que o empregador sancione e imponha suas vontades sobre as do empregado.

Essa imposição é possível através do poder de direção do empregador que advém do atributo da subordinação, este poder é encarado como uma consequência natural das negociações laborais do contrato de trabalho, conforme descreve Arion Sayão Romita:

A subordinação pode ser então explicada pelo poder de determinação ou de conformação do conteúdo das prestações derivadas pelo empregado, que o contrato e a qualificação profissional do obreiro só genericamente predeterminam. Por força do contrato de trabalho, o empregado põe sua atividade profissional à disposição do empregador. Este, em consequência, adquire o direito de dirigir a tarefa que o trabalhador desempenhará. Em outras palavras, o empregador, em troca do pagamento de uma remuneração, assume a faculdade de dispor sobre a forma de utilizar a energia que o trabalhador cola à sua disposição. Por isso, já se afirmou que a subordinação é o lado passivo do poder de comando do empregador, isto é, a faculdade que lhe é reconhecida de determinar (por meio de comandos mais ou menos genéricos) o conteúdo das prestações de trabalho. ${ }^{37}$

\footnotetext{
${ }^{36}$ RAMOS FILHO, Wilson. Direito Capitalista do Trabalho: História, Mitos e Perspectivas no Brasil. São Paulo: LTr, 2012, p. 95.

${ }^{37}$ ROMITA, Arion Sayão. A subordinação no contrato de trabalho. Rio de Janeiro, Forense, 1979. p. 73.
} 
REFLEXÕES ENTRE REGULAÇÃO E A SUPRESSÃO DE DIREITOS A PARTIR DA PESSOALIDADE E SUBORDINAÇÃO NO DIREITO CAPITALISTA DO TRABALHO

Este poder de direção concede ao empregador a possibilidade de dirigir, regulamentar e disciplinar no ambiente da empresa toda a atividade laboral. Ou seja, a subordinação acaba por ser um poder de evidente desequilíbrio inserido na relação de emprego, tendo em vista que uma das partes possui diversas prerrogativas sobre a outra que, apesar de formalmente livre, necessita subordinar-se à relação de emprego que the é apresentada.

Visualizando as discrepâncias relativas ao poder diretivo, adverte Wilson Ramos Filho a respeito dos riscos inerentes à concessão deste amplo poder:

A concentração de tamanho poder em um só polo da relação de trabalho, contudo é problemática. Conforme analogia frequente, na medida em que estabelece as normas aplicáveis a uma comunidade de empregados, dita de que modo, em que tempo e com que intensidade tais normas devem ser cumpridas, e, ainda concentra o poder de sancionar as condutas desviantes da norma, o poder de subordinar se assemelharia às ditaduras, nas quais estariam enfeixados na figura tirânica do mandatário os Poderes legislativo, Executivo e Judiciário. Além deste caráter tirânico original, à tamanha concentração de poder, a doutrina trabalhista tradicional acrescentou o poder de subordinar de modo arbitrário. A arbitrariedade que caracteriza o uso concreto do poder de subordinar, no campo do Direito do Trabalho, aparece sob o simpático da 'elasticidade' (em oposição à 'rigidez', conotada negativamente) como signo 'democrático'[...]. ${ }^{38}$

Com o Direito Capitalista do Trabalho o empregador passou a possuir um meio legal e legitimado pelo Estado de impor a subordinação aos seus empregados, para que estes ajam da maneira que o empregador entender ser a mais adequada, sendo que este agir fora determinado através do poder regulamentar, as determinações criadas pelo poder regulamentar serão executadas e ordenadas com base no poder direção do empregador e, caso o empregado não obedeça as direções e regulamentações autoritárias do empregador, o poder disciplinar também poderá ser utilizado com a finalidade de sancionar os sujeitos que não respeitem as regulamentações impostas pela parte empregadora da relação trabalhista.

Mostra-se irrefutável a existência de tamanha desproporção causada pela subordinação no Direito Capitalista do Trabalho e o seu objetivo em atribuir ao empregador todas as ferramentas para a manutenção da ordem capitalista no ambiente de trabalho, conforme acima explanado, o empregador passa a possuir o direito de regulamentar, dirigir e punir, em contrapartida o empregado passa apenas a submeter-se às vontades do empregador.

\footnotetext{
${ }^{38}$ RAMOS FILHO, Wilson. Direito Capitalista do Trabalho: História, Mitos e Perspectivas no Brasil. São Paulo: LTr, 2012, p.97.
} 
REFLEXÕES ENTRE REGULAÇÃO E A SUPRESSÃO DE DIREITOS A PARTIR DA PESSOALIDADE E SUBORDINAÇÃO NO DIREITO CAPITALISTA DO TRABALHO

No mesmo sentido, Wilson Ramos Filho descreve que a subordinação na relação de trabalho é uma:

[...] atribuição de poder por parte do Direito Capitalista do Trabalho a um dos contratantes para que o capital, agora detentor de um direito assegurado pelas normas jurídicas estatais, imponha à outra parte, nos contratos de trabalho, uma determinada ordem (regulamentando, disciplinando, fiscalizando e punindo as condutas desviantes desta ordem criada pelo capitalismo à sua imagem e semelhança) e um determinado sentido na organização da produção, assegurado pelos métodos de gestão das empresas. ${ }^{39}$

Conforme explanado acima, este ramo do Direito proporciona uma justificativa eticamente plausivel para a existência de um poder em que, baseado na contratação, possa subjugar e subordinar uma das partes contratantes à vontade da outra parte contratante, mesmo encarando que ambas possuam suas liberdades asseguradas e sejam formalmente iguais.

O Direito Capitalista do Trabalho, opera, também, por outros meios para fortalecer a subordinação entre empregado e empregador, ao sistematicamente informar-se sobre os acontecimentos provindos das relações laborais e os regulando juridicamente.

Ao alimentar-se da fonte dos fatos laborais, o Direito do Trabalho, operado pelo Estado, sistematiza e descreve as ações dos trabalhadores, normatizando-as de forma a forçá-las a adequar-se às diretrizes estabelecidas pelo Direito Capitalista do Trabalho.

Isto é, as atividades exercidas pelos trabalhadores são limitadas pelo Direito do Trabalho, sendo necessário o cumprimento de diversas imposições determinadas pelo Direito do Trabalho para que ações como a greve passem a ser toleradas pelo Direito.

Assim, a subordinação do empregado extrapola o limite das imposições do empregador, desta forma o empregado passa a ser, também, subordinado ao próprio Direito do Trabalho que, ao exigir diversas condutas do trabalhador, para que este exerça seus direitos, passa a limitar e subordinar o empregado perante o empregador.

Outro questionamento acerca da subordinação se dá pela não determinação precisa da obrigação do empregado, em que pese as relações laborais serem estabelecidas, habitualmente, com a descrição das tarefas a serem realizadas pelo empregado, estas tarefas muitas vezes podem ser substituídas por outros deveres, pois se torna impossível predeterminar todas as possibilidades de deveres que ocorrerão no momento da efetiva prestação laboral.

${ }^{39}$ RAMOS FILHO, Wilson. Direito Capitalista do Trabalho: História, Mitos e Perspectivas no Brasil. São Paulo: LTr, 2012, p.98. 
REFLEXÕES ENTRE REGULAÇÃO E A SUPRESSÃO DE DIREITOS A PARTIR DA PESSOALIDADE E SUBORDINAÇÃO NO DIREITO CAPITALISTA DO TRABALHO

Alerta Alain Supiot que esta indeterminação da obrigação reflete na subordinação do empregado, aumentando o seu campo de alcance. Levando em consideração que quanto maior a indeterminação da obrigação, maior será o poder de subordinar do empregador:

O vínculo de subordinação é, desde logo, incompatível com a exigência de uma determinação precisa da obrigação do trabalhador. Como notava Paul Durand 'o direito de direção permite ao empregador utilizar a força de trabalho do assalariado do modo que melhor convenha aos interesses da empresa. 0 contrato de trabalho limita-se, com efeito, a colocar o trabalhador à disposição do empregador: a obrigação do trabalhador comporta, em geral, uma larga indeterminação. Este direito imprime às relações de trabalho a sua marca distintiva. Nos outros contratos, o credor fixa somente, de acordo com o devedor o objeto da obrigação. No contrato de trabalho, o empregador adquire um direito de direção do contrato' ${ }^{40}$

Portanto, a subordinação trata-se de um elemento de suma importância para a utilização do poder de direção no ambiente de trabalho, sendo ressaltado quando o fator da determinação da obrigação do contrato de trabalho não é preenchido de forma adequada, ressaltando a subordinação e, consequentemente, os poderes derivados do poder de direção.

Inserido no Direito Capitalista do Trabalho, a subordinação tem como particularidade ser um dos principais elementos que proporcionam a consecução dos propósitos deste singular ramo do Direito.

Propósitos decifrados por Wilson Ramos Filho, o qual descreve o Direito Capitalista do Trabalho como uma ferramenta que trabalha em prol da manutenção da atual sociedade:

Sendo assim, em cada um dos Poderes do Estado, da resultante da correlação de forças que se estabelecer a partir da desestabilização da paz social dependerá o novo conteúdo do Direito do trabalho, que, ainda que se metamorfoseie para passar a proteger menos os empregadores e mais a classe trabalhadora, seguirá sendo ambivalente, conservador, pacificador e tutelar das relações de trabalho para manter a classe trabalhadora no 'seu devido lugar', ou seja, no lugar de classe subordinada ao poder do empregador e ao modo de vida propugnado pelo modo de produção. Em síntese, ainda que democratize e passe a tutelar de modo distinto as relações entre empregadores e empregados, inaugurando uma quinta etapa de seu desenvolvimento no Brasil, a regulação das relações entre as classes sociais e a distribuição do poder entre estas e das possibilidades de acesso a bens em cada classe social seguirá sendo feita pelo Direito Capitalista do Trabalho, o mais capitalista dentre os distintos ramos do Direito. ${ }^{41}$

\footnotetext{
${ }^{40}$ SUPIOT, Alain. Crítica do Direito do Trabalho. Lisboa, Fundação Calouste Gulbenkian, 2016. p. 159.

${ }^{41}$ RAMOS FILHO, Wilson. Direito Capitalista do Trabalho: História, Mitos e Perspectivas no Brasil. São Paulo: LTr, 2012, p. 466.
} 
REFLEXÕES ENTRE REGULAÇÃO E A SUPRESSÃO DE DIREITOS A PARTIR DA PESSOALIDADE E SUBORDINAÇÃO NO DIREITO CAPITALISTA DO TRABALHO

No mesmo sentido, Luiz Fernando Coelho expõe o Direito do Trabalho ao denunciar o caráter alienante de seu princípio protetor:

O princípio protetor reforça a ideologia do Estado neutro e protetor, mas sua função alienante está na elisão dos verdadeiros motivos que animam o direito do trabalho numa sociedade dividida em classes, que é manter a divisão social do trabalho e dificultar ao máximo que se concretizem os objetos dos movimentos sociais; e, assim, os limites da proteção podem ser claramente definidos no seguinte enunciado: é preciso proteger o operário e suprir-lhe as necessidades básicas, contanto que ele continue operário. ${ }^{42}$

Em suma, o contrato de trabalho e os elementos da pessoalidade e da subordinação são construções jurídicas que visam a manutenção do modo social de produção dominante, utilizando-se de construções jurídicas para solucionar a questão da submissão de uma pessoa livre às vontades de outra.

Porém, como constatado neste artigo, a discrepância de poderes entre o empregado e o empregador são imensas, a construção jurídica da subordinação apenas confirma e subsidia o poder diretivo do empregador, o qual tem respaldo do Estado e do Direito para efetuar e impor todas as ações necessárias para a atividade produtiva.

Do mesmo modo, incrementando a subordinação e a limitação decorrente dela, o Direito Capitalista do Trabalho opera de modo a normatizar os movimentos efetuados pelos trabalhadores, restringindo, ao legislar sobre, as atitudes que poderiam contrapor-se às vontades do empregador, restando poucas possibilidades do empregado resistir ao empregador e quando o fizer deverá seguir os critérios estabelecidos pelo Direito Capitalista do Trabalho sob pena de sofrer sanções estabelecidas por este ramo do Direito.

Ou seja, ao observar brevemente alguns aspectos insertos no Direito Capitalista do Trabalho, é possível compreender o ambiente desfavorável em que o empregado se encontra inserido, em que pese as melhorias alcançadas através do Direito do Trabalho, o empregado encontra-se envolto em um sistema que apenas visa a sua própria manutenção, levando em conta o trabalhador apenas como mais um fator de produção.

\footnotetext{
${ }^{42}$ COELHO, Luiz Fernando. Teoria Crítica do Direito. Belo Horizonte, Del Rey, 2003, p. 541.
} 


\section{CONCLUSÃO}

Nesta atual pesquisa em curso entende-se que, atualmente, o contrato de trabalho tem papel fundamental no estabelecimento e concretização do Direito Capitalista do Trabalho, operando como um instrumento que viabiliza de forma legal a instituição de uma relação jurídica de submissão de um homem livre a outro, apesar de substancialmente não ser possível a estipulação do contrato de trabalho, pois este não cumpre os requisitos necessários para enquadrar-se como espécie de negócio jurídico.

Inegável a constatação da liberdade e ganhos de direitos aos trabalhadores proporcionados pela regulação do Direito do trabalho e a instituição da relação contratual no ramo laboral, porém, ao analisar esta suposta liberdade contratual, obtém-se que a única liberdade do empregado é a liberdade de escolher a qual empregador ele irá submeter-se, ainda sendo necessário que o mercado de trabalho esteja em uma condição de pleno emprego para que esta opção do empregado possa ocorrer, ou seja, esta liberdade torna-se de difícil exercício, sendo que o empregado acaba por submeter-se aos empregadores e empregos que lhe são apresentados no mercado.

Por sua vez, os elementos que irradiam das relações laborais estabelecidas pelo contrato de trabalho, a pessoalidade e a subordinação, determinam o estado em que o empregado está submetido dentro do sistema capitalista de produção, os quais encontram respaldo na regulação propiciada pelo Direito Capitalista do Trabalho.

A pessoalidade, assim como o próprio Direito do Trabalho, possui caráter ambivalente em relação aos empregados, ao propiciar o reconhecimento da essencialidade do corpo humano na prestação laboral acaba por fundamentar as proteções prestadas ao trabalhador, entretanto também possibilita a ocorrência da individualização do empregado fragilizando as conquistas dos trabalhadores no campo coletivo ao afastá-lo do alcance das estruturas coletivas de proteção, como os sindicatos.

A subordinação certifica na relação laboral o desnível de poderes entre o empregador e os empregados, justificando o poder de direção. Do mesmo modo, justifica as medidas tomadas pelo empregador para manter o empregado nos ditames necessários à produção capitalista de produção, concedendo ao empregador tanto o poder para criar regras, poder regulamentar, quanto o poder para punir o descumprimento das regras criadas por ele, tornando favorável ao 
REFLEXÕES ENTRE REGULAÇÃO E A SUPRESSÃO DE DIREITOS A PARTIR DA PESSOALIDADE E SUBORDINAÇÃO NO DIREITO CAPITALISTA DO TRABALHO

empregador o implemento das ações que entender necessárias para o cumprimento de suas urgências produtivas.

Os poderes do empregador, baseados na subordinação e no poder de direção, são plenamente exercíveis perante o empregado que não possui meios para impor-se. Resta ao empregado amparar-se nas normas cogentes do Direito do Trabalho, as quais, como abordado neste artigo, apesar de proteger e proporcionar uma gama de direitos aos empregados, os hipossuficientes da relação laboral, propiciam que a existência do desbalanceamento de poderes mantenha-se.

No Brasil, no ano de 2016, ressurge a movimentação política e social clamando pela efetivação de propostas que visam a reforma do Direito do Trabalho, sendo as principais delas a que amplia o alcance da terceirização e a que determina a prevalência do negociado sobre o legislado. Esta afronta ao Direito do Trabalho também encontra espaço nas atuais decisões do Supremo Tribunal Federal, como por exemplo na Reclamação $n^{\circ} 24.597 / \mathrm{SP}^{43}$ a qual inviabilizou o direito de greve dos empregados públicos do HCRP-USP.

Todas estas movimentações almejam, através da precarização dos direitos trabalhistas, viabilizar o crescimento econômico e a manutenção do sistema capitalista, entretanto, deve-se frisar, o desserviço que tais medidas geram ao próprio sistema capitalista, abstrai-se do atual artigo o papel necessário e de suma importância assumido pelo Direito Capitalista do Trabalho para continuidade do atual sistema produtivo, alertando-se que as possíveis modificações no Direito do Trabalho devem ser mensuradas com extrema cautela, levando-se em conta o risco empregado ao próprio capitalismo, pois, ao deteriorar os direitos dos trabalhadores de forma irresponsável, alimenta-se o caráter revolucionário que o embate entre empregados e empregadores propicia.

Em nossos estudos anteriores, observou-se que é necessário pensar as consequências dos modelos sociais, não deixando de lado os valores humanos:

[...]pensar as consequências dos modelos sociais, o futuro do capitalismo, a viabilidade dos empreendimentos solidários sem esquecer dos processos de

\footnotetext{
${ }^{43}$ Trata-se de reclamação referente à greve deflagrada pelos empregados públicos do Hospital de Clínicas da Faculdade de Medicina de Ribeirão Preto da Universidade de São Paulo, a decisão monocrática do Ministro Dias Toffoli deferiu liminarmente que a totalidade dos empregados públicos mantivessem os serviços do hospital, impossibilitando, assim, o direito de greve destes empregados. Em sua decisão o Ministro Dias Toffoli entendeu que os empregados públicos do hospital não são inseridos no elenco dos servidores alcançados pelo direito de greve.
} 
REFLEXÕES ENTRE REGULAÇÃO E A SUPRESSÃO DE DIREITOS A PARTIR DA PESSOALIDADE E SUBORDINAÇÃO NO DIREITO CAPITALISTA DO TRABALHO

formação e enraizamento dos valores humanos e acima de tudo do resgate da dignidade dos homens[... $]^{44}$

Por fim, os elementos analisados neste artigo, juntamente com o contrato de trabalho, esclarecem o intuito e o objetivo do Direito Capitalista do trabalho e demonstram como este utiliza destas construções jurídicas para perpetuar a separação de poder e direitos entre os sujeitos da relação laboral, dando continuidade ao sistema de produção, sistema este que pode incorrer em risco caso as reformas pleiteadas no ano de 2017 não atentem-se à importância deste ramo do Direito para a manutenção do modo de produção social dominante.

\section{REFERÊNCIAS}

BARACAT, Eduardo Milléo. A boa-fé no direito individual do trabalho. São Paulo, LTr, 2003.

BARROS, Alice Monteiro de. Curso de Direito do Trabalho. 10. ed., São Paulo, LTr, 2016.

BRASIL. Supremo Tribunal Federal. Acórdão de decisão que deferiu liminarmente que a totalidade dos empregados públicos mantivessem os serviços do hospital. Reclamação $\mathrm{n}^{\circ}$ 24.597/SP. Relator: Ministro Dias Toffoli. 07 de outubro de 2016. Disponível em: http: // www.stf.jus.br/portal/processo/verProcessoAndamento.asp?incidente=501456. Acesso em: 19 mai. 2017.

BRASIL. Lei $\mathrm{n}^{\circ}$ 10.406, de 10 de janeiro de 2002. Código Civil. Brasília, Disponível em: http://www.planalto.gov.br/ccivil_03/leis/2002/L10406compilada.htm. Acesso em: 19 mai. 2017.

BRASIL. Decreto-lei $n^{\circ} 5452$, de $1^{\circ}$ de maio de 1943. Consolidação das Leis do Trabalho. Disponível em: http://www.planalto.gov.br/ccivil_03/decreto-lei/Del5452.htm. Disponível em: 19 mai. 2017.

BRASIL. Constituição Federal. Brasília: Senado Federal, 1988. Disponível em: http://www.planalto.gov.br/ccivil_03/constituicao/constituicaocompilado.htm. Acesso em: 19 mai. 2017.

COELHO, Luiz Fernando. Teoria Crítica do Direito. Belo Horizonte, Del Rey, 2003.

COUTINHO, Aldacy Rachid. Função social do contrato individual de trabalho. In COUTINHO, Aldacy Rachid et alii [Coord.]. Transformações do Direito do Trabalho. Estudos em homenagem ao Professor Doutor João Regis Fassbender Teixeira. Curitiba, Juruá, 2000.

\footnotetext{
${ }^{44}$ OPUSZKA, Paulo Ricardo. Os fundamentos das relações jurídicas do trabalho: direito do trabalho, direito ao trabalho, regulação das relações laborais, possibilidades e limites. In OPUSZKA, Paulo Ricardo[Org.]. Direito do Trabalho e Efetividade: temas clássicos, problemas contemporâneos. Curitiba, Editora CRV, 2017, p. 46.
} 
REFLEXÕES ENTRE REGULAÇÃO E A SUPRESSÃO DE DIREITOS A PARTIR DA PESSOALIDADE E SUBORDINAÇÃO NO DIREITO CAPITALISTA DO TRABALHO

DELGADO, Maurício Godinho. Curso de Direito do Trabalho.16. ed. São Paulo, LTr, 2017.

EDELMAN, Bernard. A legalização da Classe Operária. São Paulo, Boitempo, 2016.

HUBERMAN, Leo. História da riqueza do homem. 20. ed. Rio de janeiro, Zahar, 1984.

MARQUES DA FONSECA, Maíra Silva. Redução Da Jornada De Trabalho A Partir Da Análise Do

Sistema Capitalista De Produção: Fundamentos Interdisciplinares. 2011. Disponível em:

http: / /acervodigital.ufpr.br/bitstream/handle/1884/25554/DISSERTACAO\%20-

\%20Maira\%20S\%20M\%20Fonseca.pdf?sequence=1. Acesso em: 19 mai. 2017.

NASCIMENTO, Amauri Mascaro, Iniciação ao Direito do Trabalho. São Paulo, LTr, 2009.

OPUSZKA, Paulo Ricardo. Os fundamentos das relações jurídicas do trabalho: direito do trabalho, direito ao trabalho, regulação das relações laborais, possibilidades e limites. In OPUSZKA, Paulo Ricardo [Org.]. Direito do Trabalho e Efetividade: temas clássicos, problemas contemporâneos. Curitiba, Editora CRV, 2017.

PORTILHO, Raphaela Magnino Rosa. O Direito do Trabalho na Visão Crítica de Alain Supiot. 2014. Disponível em: http://www.publicadireito.com.br/artigos/?cod=092cb9ab3aaf99bd. Acesso em: 19 mai. 2017.

RAMOS FILHO, Wilson. Direito Capitalista do Trabalho: História, Mitos e Perspectivas no Brasil. São Paulo, LTr, 2012.

ROMITA, Arion Sayão. A subordinação no contrato de trabalho. Rio de Janeiro, Forense, 1979.

ROMITA, Arion Sayão. O poder disciplinar do empregador. Rio de Janeiro: Biblioteca Jurídica Freitas Bastos, 1983.

SINGER, PAUL. Aprender Economia. 9. ed. São Paulo: Brasiliense, 1988.

SUPIOT, Alain. Crítica do Direito do Trabalho. Lisboa: Fundação Calouste Gulbenkian, 2016.

SUPIOT, Alain. Homo Juridicus: ensaio sobre a função antropológica do Direito. Lisboa: Instituto Piaget, 2005.

Recebido em: 02/06/2017 / Aprovado em: 13/07/2017.

\section{COMO CITAR O ARTIGO (ABNT)}

LIMA, Erick Alan; OPUSZKA, Paulo Ricardo. REFLEXÕES ENTRE A REGULAÇÃO E A SUPRESSÃO DE DIREITOS A PARTIR DA PESSOALIDADE E SUBORDINAÇÃO NO DIREITO CAPITALISTA DO TRABALHO. Revista Eletrônica do Curso de Direito da UFSM, Santa Maria, RS, v. 12, n. 2, p. 620-647, ago. 2017. ISSN 1981-3694. Disponível em:

<https://periodicos.ufsm.br/revistadireito/article/view/27499>. Acesso em: dia mês. ano.

doi:http://dx.doi.org/10.5902/1981369427499. 